\title{
Geomagnetic storms driven by ICME- and CIR-dominated solar wind
}

\author{
M. H. Denton, ${ }^{1,2}$ J. E. Borovsky, ${ }^{1}$ R. M. Skoug, ${ }^{1}$ M. F. Thomsen, ${ }^{1}$ B. Lavraud, ${ }^{1}$ \\ M. G. Henderson, ${ }^{1}$ R. L. McPherron, ${ }^{3}$ J. C. Zhang, ${ }^{4}$ and M. W. Liemohn ${ }^{4}$ \\ Received 19 September 2005; revised 17 November 2005; accepted 7 February 2006; published 18 May 2006.
}

[1] The interaction of the solar wind and the Earth's magnetosphere is complex and the phenomenology of the interaction is very different for solar wind dominated by interplanetary coronal mass ejections (ICMEs) compared to solar wind dominated by corotating interaction regions (CIRs). We perform a superposed epoch study of the effects of ICME- and CIR-dominated solar wind upon the storm-time plasma at geosynchronous orbit using data from the magnetospheric plasma analyzer (MPA) instruments on board seven Los Alamos National Laboratory (LANL) satellites. Using 78 ICME events and 32 CIR events, we examine the electron and ion plasma sheets that are formed during each type of solar wind driver, at energy-per-charge between $\sim 0.1$ and $45 \mathrm{keV} / \mathrm{q}$. The results demonstrate that CIR events produce a more significant modulation in the plasma sheet temperature than ICME events, whilst ICME events produce a more significant modulation in the plasma sheet density than CIR events. We attribute these differences to the average speed in the solar wind and a combination of the density of the solar wind and the ionospheric component of the plasma sheet, respectively. We also show that for CIR events, the magnitude of the spacecraft potential is, on average, significantly greater than during ICME-events, with consequent effects upon the performance of instrumentation within this environment.

Citation: Denton, M. H., J. E. Borovsky, R. M. Skoug, M. F. Thomsen, B. Lavraud, M. G. Henderson, R. L. McPherron, J. C. Zhang, and M. W. Liemohn (2006), Geomagnetic storms driven by ICME- and CIR-dominated solar wind, J. Geophys. Res., 111, A07S07, doi:10.1029/2005JA011436.

\section{Introduction}

[2] The outflow of plasma from the sun, generally known as the solar wind, induces significant effects within the Earth's magnetosphere when the two interact. The characteristics of the solar wind are highly variable, and in this report we focus on two specific types of disturbance in the solar wind and subsequent effects in the inner magnetosphere. Coronal mass ejections (CMEs) occur when material is catastrophically ejected from the sun, and these events are typically most numerous close to the sunspot maximum [e.g., MacQueen et al., 1986; Hundhausen, 1993, and references therein]. In contrast, corotating interaction regions (CIRs) are large-scale structures in the heliosphere which occur predominantly during the declining phase of the solar cycle. CIRs occur in response to the interaction of fast and slow solar winds and, since they are related to the fast solar wind arising from coronal holes, they may recur with a $\sim 27$ day period [e.g., Smith and Wolf, 1976; Gosling

\footnotetext{
${ }^{1}$ Space Science and Applications (ISR-1), Los Alamos National Laboratory, Los Alamos, New Mexico, USA.

${ }^{2}$ Now at School of Physics and Astronomy, University of Southampton, Southampton, UK.

${ }^{3}$ Institute of Geophysics and Planetary Physics, University of California, Los Angeles, Los Angeles, California, USA.

${ }^{4}$ Atmospheric, Oceanic and Space Sciences Department, University of Michigan, Ann Arbor, Michigan, USA.

Copyright 2006 by the American Geophysical Union. 0148-0227/06/2005JA011436
}

et al., 1978, 1981; Crooker and Cliver, 1994; Tsurutani et al., 1995, and references therein].

[3] With regard to the magnetosphere, previous studies have highlighted the broad magnetospheric effects of CMEs and CIRs [e.g., Kamide et al., 1998; Wilken et al., 1999; Gonzalez et al., 2002, and references therein], whilst the effects of CMEs and CIRs in the region of low-Earth orbit have also been the subject of recent investigation [e.g., Dmitriev et al., 2005]. A recent report by Borovsky and Denton [2006] contains a review of the differences between CME- and CIR-dominated solar wind and examines the respective signatures of each in a number of regions, including the solar wind, the magnetosphere, and the auroral zone.

[4] The temporal and spatial evolution of geomagnetic storms has been the subject of intense experimental and theoretical study even prior to the space age and numerous studies of the storm process are present in the literature. A recent study by Denton et al. [2005] contains a superposed epoch study of 283 geomagnetic storms between 1991 and 2001. The authors show that the hot electron $(\sim 0.03-$ $45 \mathrm{keV})$ and hot ion ( 0.1-45 keV) densities and temperatures in the plasma sheet are strongly correlated with the phase of a geomagnetic storm and also that significant temporal and spatial changes occur in the plasma in the periods before and after minimum storm Dst. In the current study the aim is to analyze the structure and temporal evolution of plasma at geosynchronous orbit during storms induced by solar wind dominated by material from CMEs 
(usually termed interplanetary coronal mass ejections (ICMEs)) and compare these data with periods when the solar wind is dominated by CIRs, the goal being to determine how the magnetosphere responds to each type of driver. We use data from seven magnetospheric plasma analyzer (MPA) instruments on board Los Alamos National Laboratory (LANL) satellites in geosynchronous orbit to achieve this aim. LANL/MPA data are analyzed for a set of 78 ICME-dominated solar wind events and compared with data from a set of 32 CIR-dominated solar wind events, using a superposed epoch technique. Specifically, and as an extension of the Denton et al. [2005] study, we perform a superposed epoch analysis of LANL/MPA geosynchronous data from ICME- and CIR-dominated solar wind intervals to determine the storm time and local time variation of the ion and electron density and temperature for each type of solar wind driver.

[5] Geosynchronous orbit is an ideal location from which to study plasma sheet access to the inner magnetosphere and LANL/MPA data have been used extensively to study the region and its structure and temporal evolution [e.g., Thomsen et al., 1998, 2001, 2003; Borovsky et al., 1998; Korth et al., 1999; Friedel et al., 2001; Korth and Thomsen, 2001; Denton et al., 2005; Lavraud et al., 2005]. Geosynchronous orbit typically lies within the nightside plasma sheet over a range of local time that is wider for stronger convection [e.g., Korth et al., 1999]. Since the plasma sheet is known to be a significant source of the ring current, the observed differences in the properties of the plasma sheet injected to the inner magnetosphere during ICME and CIR events are useful to determine the character, composition and strength of the subsequent ring current. Such information is also likely to assist in providing realistic boundary conditions for physics-based ring current models which use geosynchronous data as an input [e.g., Jordanova et al., 1997; Liemohn et al., 2001].

\section{Instrumentation}

[6] Data for this study are provided by the MPA instruments flown by LANL on seven satellites located in geosynchronous orbit. The MPA instrument is an electrostatic analyzer which measures the three-dimensional energy-per-charge distributions of ions and electrons at energies $\sim 1-45 \mathrm{keV} / \mathrm{q}$ at a time cadence of one ten-second snapshot every $86 \mathrm{~s}$. For this study we use the spin-averaged moments computed from the full distributions which provide density and temperature measurements for the electrons and ions [Thomsen et al., 1998].

[7] Typically, the moments of the particle distribution for the hot electrons in the energy range $\sim 0.03-45 \mathrm{keV}$ and the hot protons in the energy range $\sim 0.1-45 \mathrm{keV}$ are calculated under the assumption that the entire ion population consists of protons. A full description of the LANL/MPA instrument may be found in the work of Bame et al. [1993] and McComas et al. [1993].

\section{Data Selection and Analysis}

[8] Initially, two subsets of the entire LANL/MPA dataset are examined using a superposed epoch analysis technique that is equivalent to that employed by Denton et al. [2005].
First, the list of ICME events (1996-2002) from Cane and Richardson [2003] is studied, and the time interval during which each ICME occurred is noted. Then the Dst index is examined and the zero epoch of each event is set to the time of the first clear minimum that occurs in the index following the ICME arrival at the magnetopause (this time must occur at least one hour following the ICME start time). Events are rejected when either (1) a subsequent event occurs within the 72 hours after the initial event, or (2) no clear minimum in Dst occurs in the period following the ICME arrival, indicating possibly disturbed conditions within the magnetosphere when the ICME arrived. We neglect effects due to the structure within the ICME itself [e.g., Zhang et al., 2004]. The aim of rejecting such events is to only use "clean" storms in the subsequent analysis, rather than events where the nature of the storm may be masked by an already disturbed magnetosphere. Application of these criteria provides a list of the times of minimum Dst following the impact of ICME-dominated solar wind on the magnetosphere between 1996 and 2002, a total of 78 events, hereafter referred to as Group A events.

[9] To obtain a list of CIR-dominated solar wind events, solar wind data taken by the WIND spacecraft between 1994 to 2002 are analyzed and a number of stream interfaces identified, based upon their typical signatures in the solar wind (see references in section 1), specifically, (1) the solar wind velocity changes from less than $350 \mathrm{~km} \mathrm{~s}^{-1}$ to more than $550 \mathrm{~km} \mathrm{~s}^{-1},(2)$ the solar wind density peaks slowly and drops suddenly at the interface, (3) the total magnetic field attains a maximum, and (4) the azimuthal flow angle of the solar wind plasma changes from west of the Sun to east of the Sun, with the interface at the zero crossing of angle. The Dst index is then examined and the zero epoch for each event is set to the time of the first clear minimum in Dst following the CIR arrival at the magnetopause (at least one hour after the identification of a CIR at the orbit of the WIND spacecraft). Again, events are rejected when either (1) a subsequent event occurs within the 72 hours after the initial event or, (2) no clear minimum in Dst occurs in the period following the CIR arrival. These criteria provide a list of the times of minimum Dst following the arrival of CIR-dominated solar wind at the magnetosphere, a total of 32 events, subsequently referred to as Group C events.

[10] The Dst index is chosen to order the storms even though ICME-dominated solar wind generally causes a larger signature in Dst compared to CIR-dominated solar wind. Our primary interest is the nature of the storm induced by different types of solar wind and the effects upon the plasma sheet population, and subsequent ring current. The minimum Dst for each storm gives a convenient way to perform a superposed epoch analysis, particularly since the Dst index is influenced by the ring current strength. Also, it should be noted that by analyzing data from a full day before the minimum Dst to two and a half days after minimum Dst, we are sure to encompass the effects of the ICME or CIR. To compare between storms of similar size, a further subset of the Group A events is defined where the minimum storm Dst for each storm is $>-100$, a total of 45 events subsequently referred to as Group B events. The average Dst of Group B events is very similar to the Group $\mathrm{C}$ events allowing investigation of the 


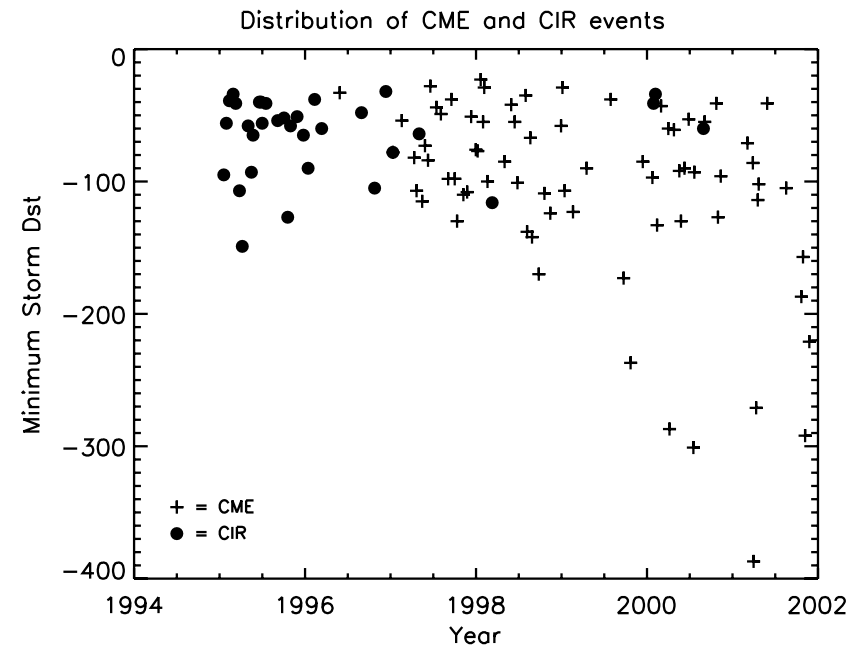

Figure 1. The distribution of ICME events and CIR events used in this study. Most CIR events occur in the declining phase of the solar cycle while ICMEs are most probable close to solar maximum. ICME events typically produce a greater signature in Dst.

effects of ICME- and CIR-driven storms, irrespective of storm size. The nature of the analysis is biased against periods when the magnetosphere is already in a disturbed state, as measured by Dst. Since we are primarily interested in the effects of storms upon a quiet magnetosphere, we do not consider such bias significant.

[11] For all groups we bin the LANL/MPA data using the same method described by Denton et al. [2005]. In that study, the LANL/MPA data were analyzed to provide the average hot electron and hot ion density, as a function of epoch time, for 283 storms between 1990 and 2001. In the current study, we take LANL/MPA measurements of hot electron and hot ion temperature and density and bin each measurement into one of 24 local-time bins and 96 epochtime bins covering the 24 hours before the zero epoch and the 72 hours after. Magnetosheath and boundary layer intervals are removed by restricting the analysis to data points where the hot ion density is less than $3 \mathrm{~cm}^{-3}$ and the perpendicular ion temperature exceeds $2000 \mathrm{eV}$. The mean of the values in each bin is calculated noting that each bin must have at least five counts or it is considered empty and plotted grey. Data are plotted from one day before the zero epoch to two and a half days after, the period when data coverage is greatest. The mean $\mathrm{Kp}$ and Dst indices are calculated during this period by taking the appropriate $\mathrm{Kp}$ and Dst for every data point and averaging the results as a function of epoch time (with the Kp index converted to a decimal value). In this way we produce plots of the mean temperature and density following a ICME- or CIR-driven storm, along with the mean $\mathrm{Kp}$ and Dst during these intervals. These indices are used as a proxy for the magnetospheric convection strength, and the ring current strength, respectively.

\section{Results}

[12] Figure 1 shows the distribution of the ICME and CIR events and the corresponding minimum Dst for each event.
As can be seen, most of the CIR events occurred close to solar minimum $(\sim 1996)$ and during the declining phase of the solar cycle. In contrast, the number of ICME events, and their strength, increased towards solar maximum $(\sim 2001)$. On average, the ICME events have a greater signature in the Dst index than the CIR events.

[13] Figure 2 shows the mean $\mathrm{Kp}$ and Dst indices for Groups A, B, and C, between 1994 and 2002, as a function of epoch time and local time. Kp values greater than $3^{\circ}$ are colored dark grey. The averaged Dst profiles of the three groups are very similar in shape, displaying a sharp fall to minimum Dst, followed by a recovery period lasting at least 24 hours. Figure 2 also indicates that while a stronger ring current is likely during ICME-driven storms, the Kp index remains elevated for much longer following the main phase of the CIR-driven storms. Since Kp is primarily a measure of the magnetospheric convection strength [e.g., Thomsen, 2004], this demonstrates that following the main phase of the CIR-driven storms, the convection is elevated for a longer period. This, in turn, implies a longer period of delivery of plasma sheet material to the inner magnetosphere for the CIR storms than for the ICME storms.

[14] For the Group A events shown in Figure 2a there is a clear storm-like Dst signature, with an average minimum Dst at zero epoch of -86.54 and an average Kp at zero epoch of $\sim 5^{\circ}$. In contrast the average Dst and Kp values at zero epoch for the Group B events in Figure $2 \mathrm{~b}$ are -55.58 and $\sim 4^{\circ}$, respectively. The averaged Dst and $\mathrm{Kp}$ for the Group $\mathrm{C}$ events shown in Figure $2 \mathrm{c}$ are -58.93 and $\sim 4^{+}$, respectively. It should be noted that the averaged Dst profiles in Figure $2 \mathrm{~b}$ and $2 \mathrm{c}$ are very similar. Thus when analyzing the data, we are able to compare the differences between ICME and CIR storms of a similar size, as measured by Dst.

[15] Figure 3 shows the averaged hot ion and hot electron densities for Group A, B, and C events, as a function of epoch time and local time. Bins colored grey indicate a lack of data, and bins colored white indicate values greater than the maximum on the color bar. A fall in the Dst index is typically accompanied by the plasma sheet moving inward of geosynchronous orbit, with the greatest increase in the ion and electron densities occurring during the main phase of the storm at, or close to, minimum Dst. The hot ion density in Figure 3a shows a significant increase around 12 hours prior to minimum Dst. The density increase occurs initially close to local midnight and then spreads in local time, until densities are increased at all local times. The density is maximized close to minimum Dst and then decreases over the next $\sim 2$ days to approximately prestorm levels. Figure $3 \mathrm{c}$ shows that when the largest events are excluded, the hot ion density follows the same trend as shown in Figure 3a, but the density at minimum Dst is lower. Figure $3 \mathrm{e}$ shows the mean hot ion density of the Group $\mathrm{C}$ events. The density behavior during these events appears quite different from that during the ICME events, even though the averaged Dst profile is very similar (compare Figure 3c with Figure 3e). The enhanced density evident in the Group $\mathrm{C}$ events is primarily restricted to the time prior to, and at, Dst minimum, and this enhancement does not spread as much in local time as during the ICME events. The density at local noon is largely unchanged during the storm. As with the ICME events, the period of 
a)
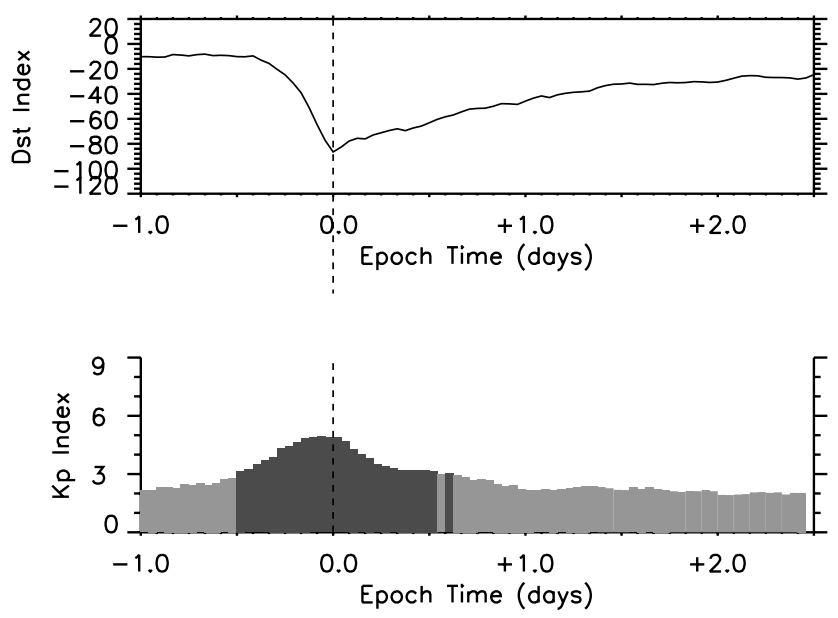

b)
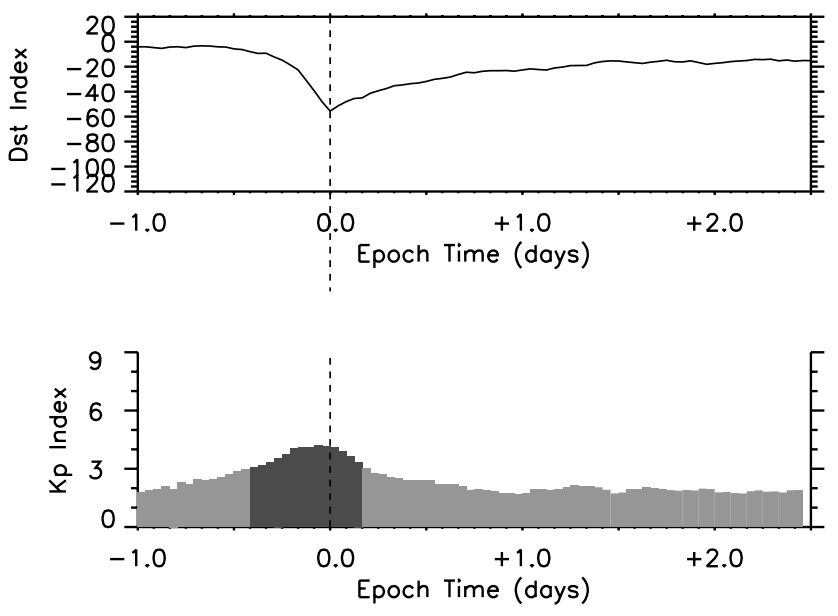

c)
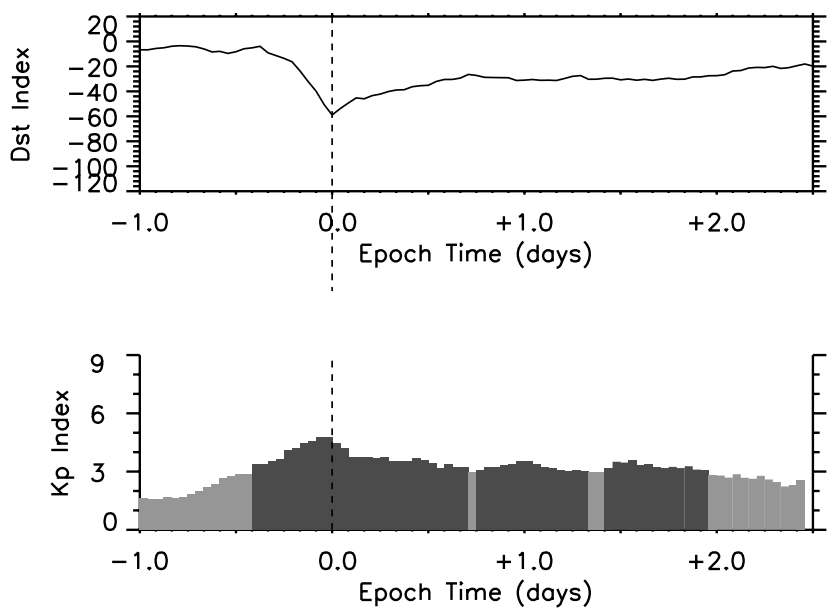

Figure 2. The mean Dst and $\mathrm{Kp}$ indices for the three data sets used in the study; (a) Group A - all 78 ICME events, (b) Group B - the 45 ICME events with minimum Dst $>-100$, and (c) Group C - the 32 CIR events, as a function of epoch time and local time. Kp values greater than 3 are colored dark grey. minimum Dst for CIR storms, is approximately the time of highest ion density, but the density returns to pre-storm levels within $\sim 24$ hours. This is much quicker than for the ICME events, even though the decay in Dst is similar for both the ICME and CIR events (see Figure 2).

[16] With regard to the electrons, the density trends in a similar way as for the ions. Figure 3 b shows that the average hot electron density for the Group A events peaks close to minimum Dst, and the peak is centered close to dawn. The initial increase in density prior to the storm also appears to be offset from local midnight towards the postmidnight sector. Electron density remains enhanced for at least 48 hours following minimum Dst. As shown by Korth et al. [1999], there is typically no increase in hot electron density between $\sim 1200$ and 1800 LT, no matter how strong the convection strength. Therefore the increase in electron density during these storms is constrained to the region between dusk and the prenoon sector. Comparing Figure $3 \mathrm{~b}$ with Figure 3d, which shows the Group B events, we see that the strength of the storms appears to be related to the subsequent hot electron density at geosynchronous orbit - the larger the storm (as measured by Dst) the greater the density [Thomsen et al., 1998; Denton et al., 2005]. Figure $3 \mathrm{f}$ shows the averaged hot electron density for the Group C events. Clearly, although the Group B and Group C storms have a very similar Dst profile, the changes in electron density during the storm are significantly different. The electron density returns to prestorm levels much faster during the CIR events than during the ICME-driven storms. This is despite the indication from the $\mathrm{Kp}$ index that the convection remains enhanced for the CIR-driven storms much longer than during both sets of ICME-driven storms.

[17] Results from the superposed analysis for the hot ion and hot electron temperatures are shown in Figure 4 for Group A, B, and C events, as a function of epoch time and local time. The temperatures are calculated by taking the average of twice the perpendicular temperature plus the parallel temperature. Figure $4 \mathrm{a}$ shows the hot ion temperature for the Group A events. Two prominent features are noticeable. First, the temperature during the main phase of the storm is typically lower at dawn than it is at dusk, a result that is true during quiet and disturbed times [Korth et al., 1999] and largely due to the different drift paths that the ions may take through the system. (The higher-energy fraction of the ions which proceed toward the dawnside are preferentially lost due to particle precipitation). Second, with regard to the changes in ion temperature during the storm, it appears that the temperature in the afternoon sector is slightly increased close to minimum Dst (to $\sim 9000 \mathrm{eV}$ ). In contrast, in the dawn sector the temperature appears to fall during the main phase and reach a minimum around zero epoch $(\sim 4000 \mathrm{eV})$.

[18] Comparing Figure 4a with Figure 4c which show the ion temperatures for the Group A and Group B events, it is evident that the size of storm may play some role in modulating the temperature of the plasma sheet, with a slightly higher temperature in the afternoon sector for the storms with a smaller Dst signature. The hot ion temperature exceeds $10,000 \mathrm{eV}$ close to noon for the smaller ICME storms, whereas the temperature is $\sim 9000 \mathrm{eV}$ for the larger ICME storms. The temperature during the Group $\mathrm{C}$ events, 
a)

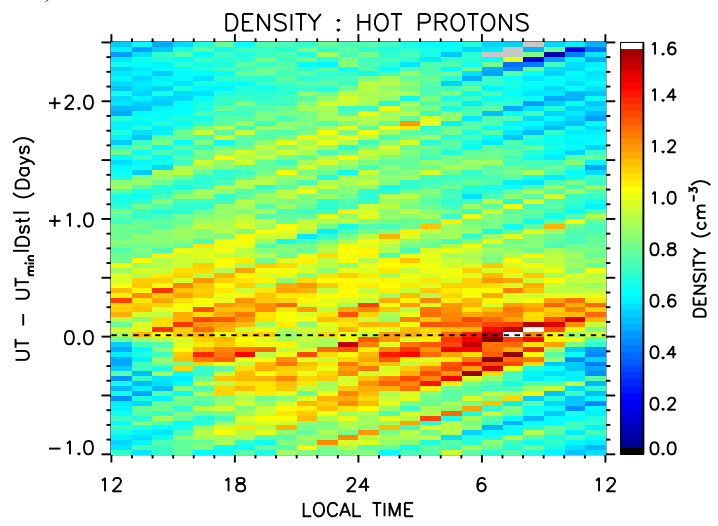

c)

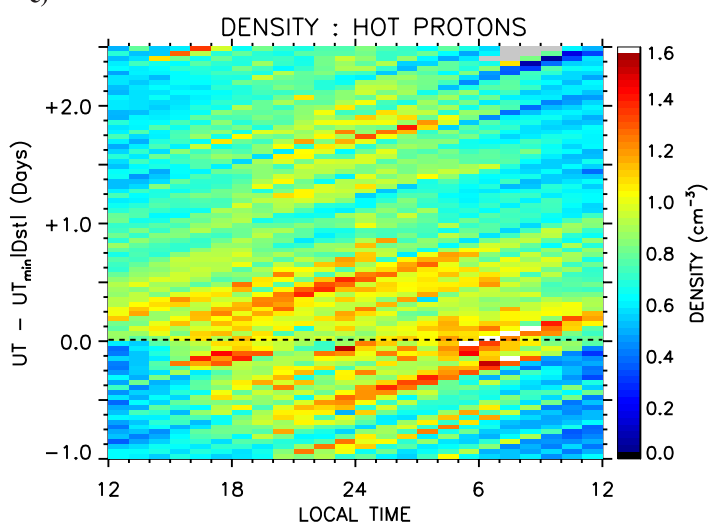

e)

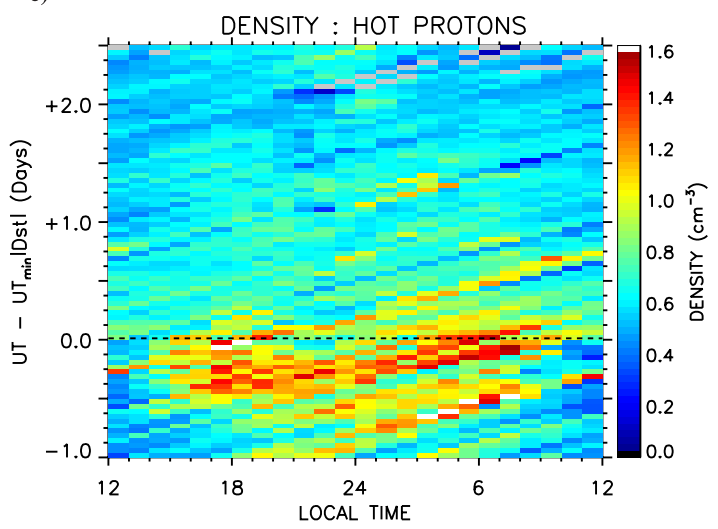

b)

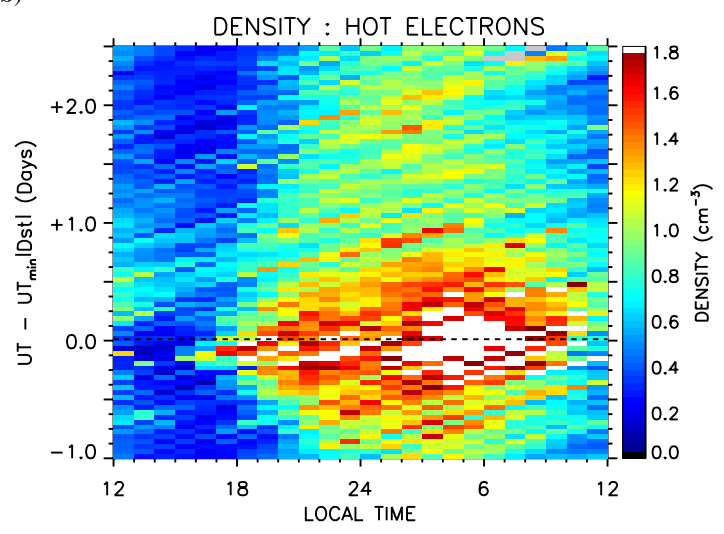

d)

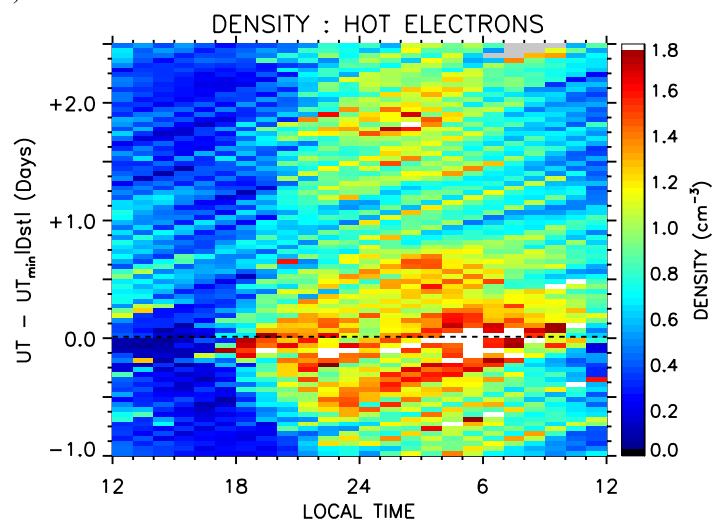

f)

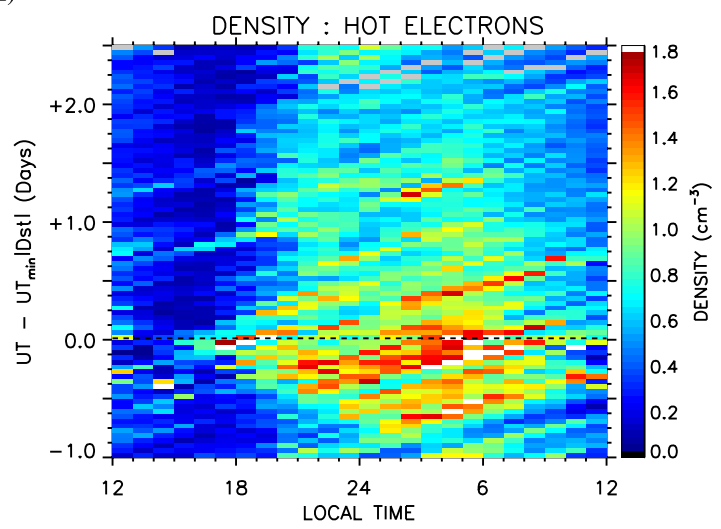

Figure 3. The hot ion and hot electron densities for the three data sets used in the study; (a) and (b) Group A - all 78 ICME events, (c) and (d) Group B - 45 ICME events with minimum Dst > - 100, and (e) and (f) Group C - 32 CIR events, as a function of epoch time and local time.

shown in Figure 4e is much higher than during the ICME storms. This result is even clearer for the electrons, with the temperature for the Group A and B storms, shown in Figure $4 \mathrm{~b}$ and $4 \mathrm{~d}$, remaining elevated for less time than for the Group C storms shown in Figure 4f. We discuss possible reasons for this observation in section 5 .

[19] In Figure 5 the measured spacecraft charging for ICME-driven and CIR-driven geomagnetic disturbances is examined. For some time it has been known that CIR-driven storms are more effective at producing relativistic electrons in the outer radiation belts than are ICME-driven storms [e.g., Paulikas and Blake, 1976; Mann et al., 2004].
Consistent with this, the occurrence frequency of internalcharging anomalies on geosynchronous spacecraft peaks during the declining phase of the solar cycle [Wrenn and Smith, 1996]. Although CIR-driven storms can produce strong spacecraft charging [e.g., Knipp et al., 1998], the occurrence frequency of spacecraft anomalies attributed to spacecraft surface charging peaks at solar maximum [Wrenn and Smith, 1996]. To further differentiate between the ICME events which produce the largest signature in Dst, we define a new group of events, Group D, which consists of the ICME events where the minimum Dst $<-100$. In Figure 5 the spacecraft-charging voltages produced by 
a)

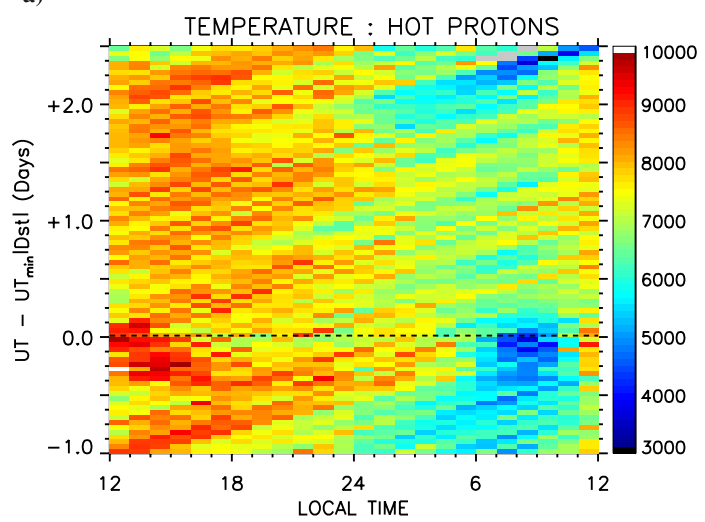

c)

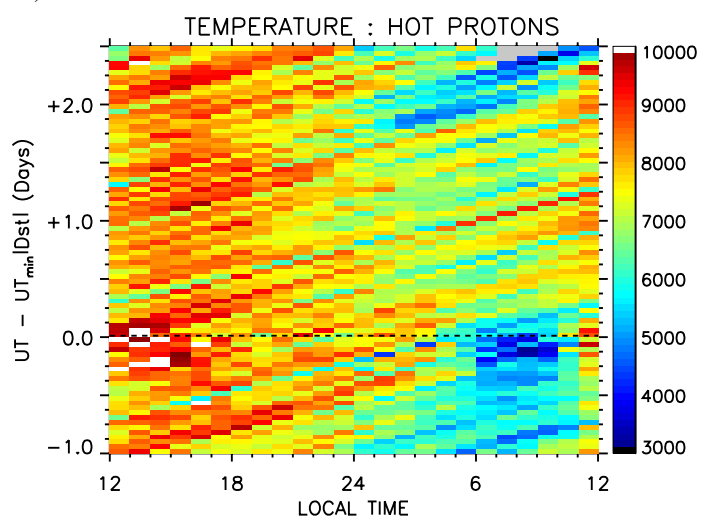

e)

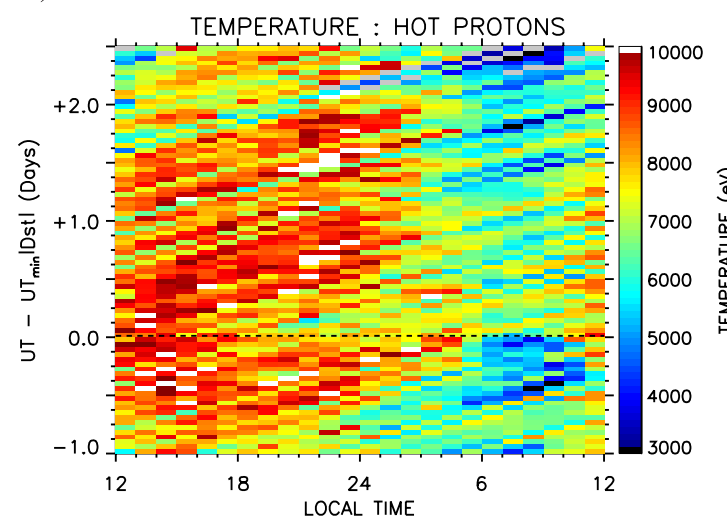

b)

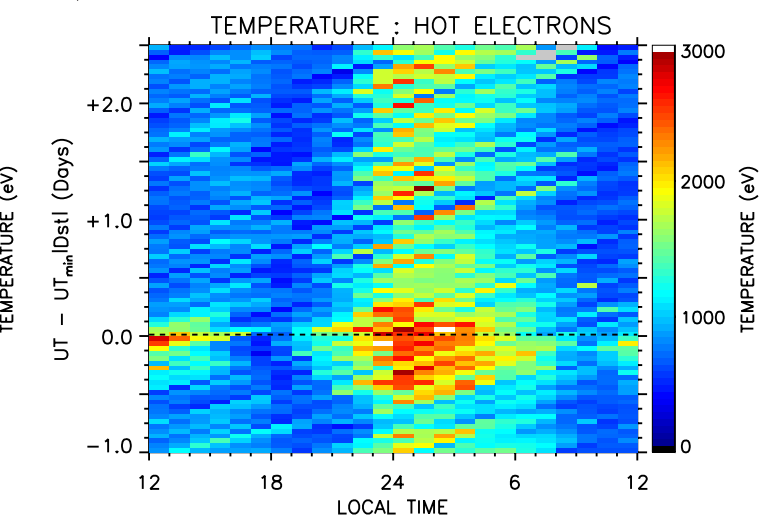

d)

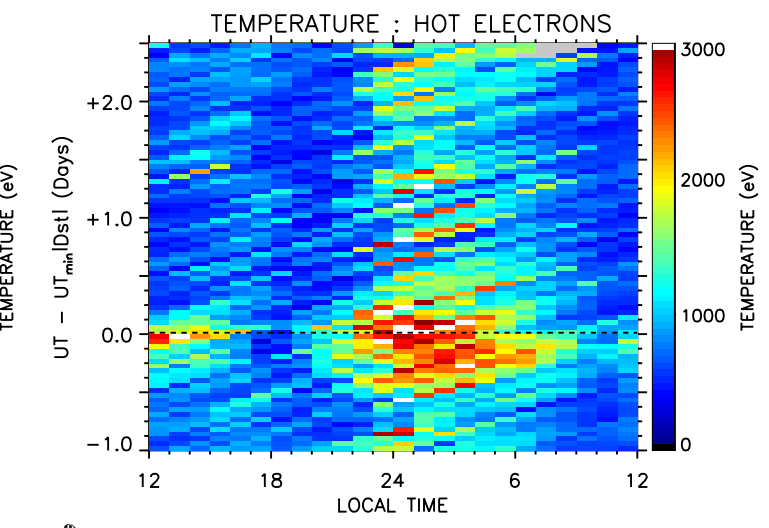

f)

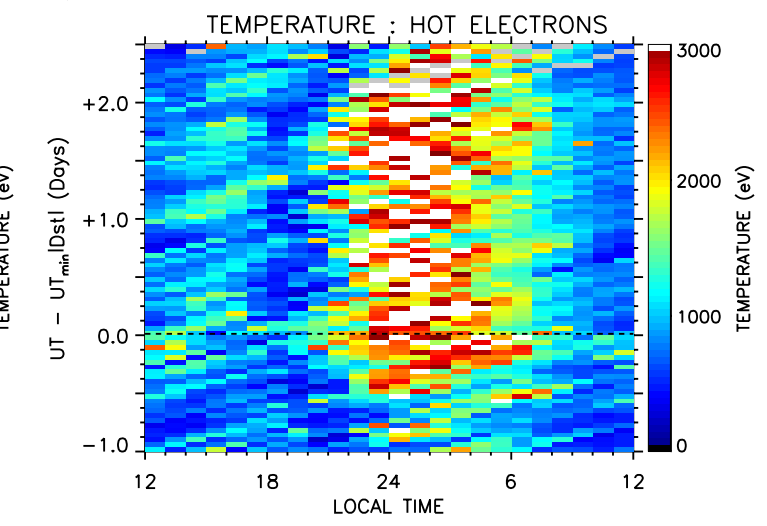

Figure 4. The hot ion and hot electron temperatures for the three data sets used in the study; (a) and (b) Group A - all 78 ICME events, (c) and (d) Group B - 45 ICME events with minimum Dst > - 100, and (e) and (f) Group C - 32 CIR events, as a function of epoch time and local time.

ICMEs and CIRs at geosynchronous orbit can be compared. Figures $5 \mathrm{a}, 5 \mathrm{~b}$, and $5 \mathrm{~d}$ pertain to ICME events and Figure $5 \mathrm{c}$ pertains to CIR events. Clearly, the levels of spacecraft charging during CIR events are higher than the levels for ICMEs, even for ICMEs that drive very strong storms (Figure 5d). Note that the measurements in Figure 5 include eclipse and noneclipse intervals; the relationship between hot plasmas and spacecraft charging differs dramatically for eclipse and noneclipse times. (The Earth's shadow falls on geosynchronous orbit for an interval of about \pm 0.5 hours of local time around local midnight near the equinoxes). In Figure 6 the eclipse intervals are removed and spacecraftcharging in noneclipse times can be examined. Again,
Figures $6 \mathrm{a}, 6 \mathrm{~b}$, and $6 \mathrm{~d}$ pertain to ICME events and Figure 6c pertains to CIR events. The levels of spacecraft charging during CIR events are statistically much higher than the levels for ICMEs, even for ICMEs that drive strong storms (Figure 6d). As can be seen in both Figure 5 and Figure 6, the duration of the charging (days for CIR events, several hours for ICMEs) is longer for CIR events and the local-time width of the charging region on the nightside is greater for CIR events. It is well known that spacecraftcharging voltages are correlated with the temperature of the ambient electrons [e.g., Garrett, 1981; Thomsen et al., 1999]; knowing this, Figures 5 and 6 are consistent with Figure 4 which shows that the electron temperatures throughout the 
a)

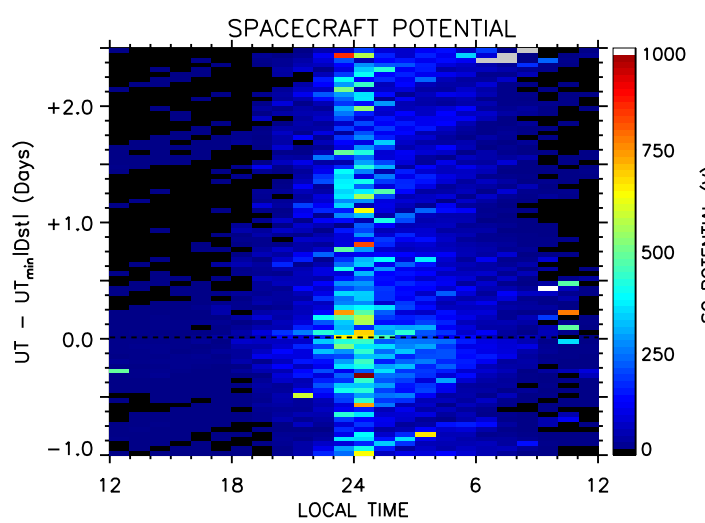

c)

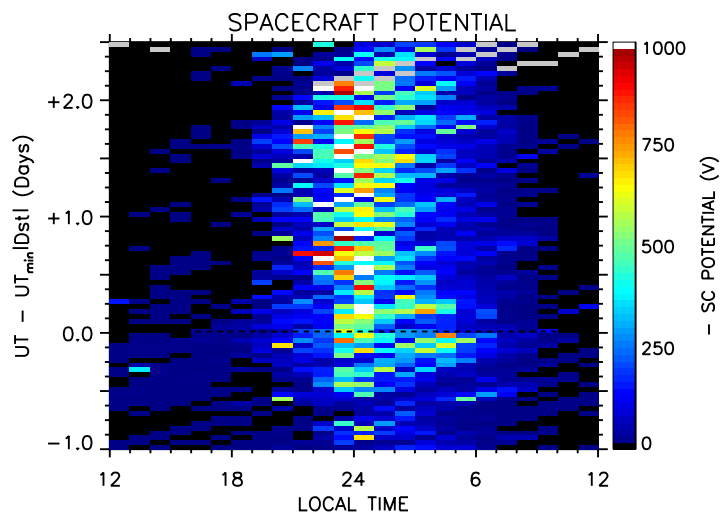

b)

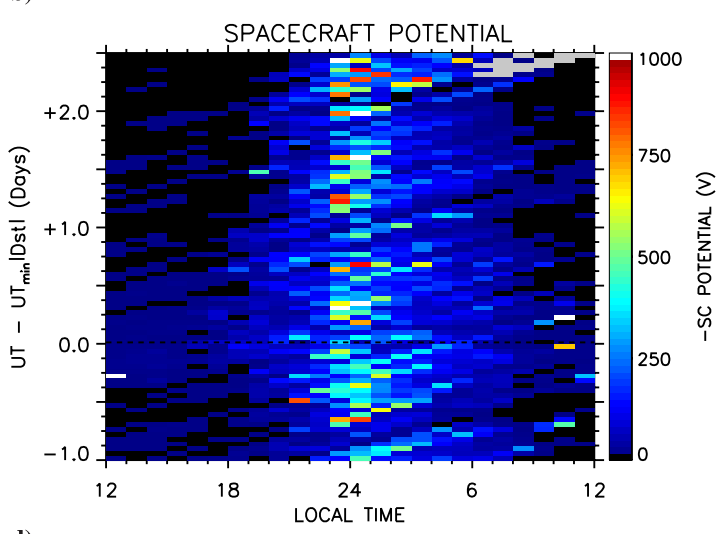

d)

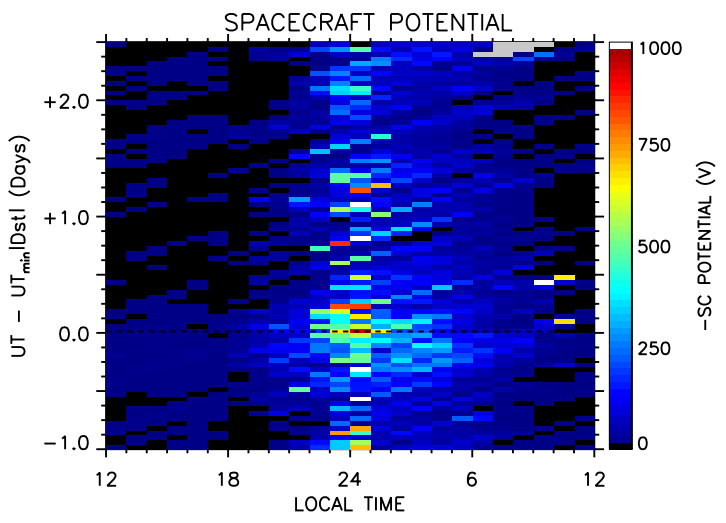

Figure 5. The averaged (negative) spacecraft potential for (a) Group A - all 78 ICME events, (b) Group B - 45 ICME events with minimum Dst > -100, (c) Group C - 32 CIR events, and (d) Group D - 33 ICME storms with minimum Dst $<-100-$, as a function of epoch time and local time. The magnitude of the spacecraft potential is much greater for the CIR events, compared with ICME events.

nightside are much higher, and remain elevated for longer, during CIR events than for ICME events.

\section{Discussion}

[20] Previous studies have well-documented the differences between ICME- and CIR-dominated solar wind (see references in section 1). The effects of each type of solar wind when it impinges upon the Earth's magnetosphere have been examined by numerous authors. Data from the Geotail spacecraft have been presented by Wilken et al. [1999] and show the broad response of the magnetosphere to ICME and CIR storms during the first half of 1994. Studies by Zong et al. [1997] and Wilken et al. [1998] highlight the response of the ion composition in the magnetotail in response to an isolated substorm and the leading phase of a CIR, respectively. A recent study by Borovsky and Denton [2006] includes a review of the differences that exist between ICME and CIR events by tabulating their character and their effects in a number of regions, including the solar wind, the magnetosphere and the auroral zone.

[21] Further investigation of the characteristics of ICMEand CIR-driven geomagnetic storms is particularly timely in view of the conclusion of Kamide et al. [1998] that ICMEs and CIRs "are found to be the primary phenomena responsible for the main phase of the geomagnetic storm." The work presented in the current study is specifically focused on the differences between ICME and CIR events in the inner magnetosphere. By separating the effects of storms caused by these different solar wind conditions, analysis of LANL/MPA data indicates that the nature of the plasma at geosynchronous orbit can be very different when ICME- or CIR-dominated solar wind interacts with the Earth's magnetosphere. A particular point to note is that the hot ion and hot electron densities for ICME-driven storms are typically much greater than for CIR-driven storms, especially after the time of minimum Dst. The electron and ion density at the time of minimum Dst appears to be directly related to the magnitude of the Dst, with higher densities during the larger storms. In addition, despite periods where the convection remains at a more elevated level during the CIR events, the density following the main phase of the storm is typically much lower for the CIR events compared with the ICME events. The reason for this is likely related to the different nature of the plasma sheet formed under ICMEand CIR-dominated solar wind conditions. It is clear that the plasma sheet density is directly related to the size of the storm, when driven by an ICME. What is also clear is that CIR events coincide with a plasma sheet that has a significantly lower density than that measured during ICME events, even when the storms, as measured by Dst, are equivalent in size. Since the density of the plasma sheet is strongly coupled with the density of the ambient solar wind 
a)

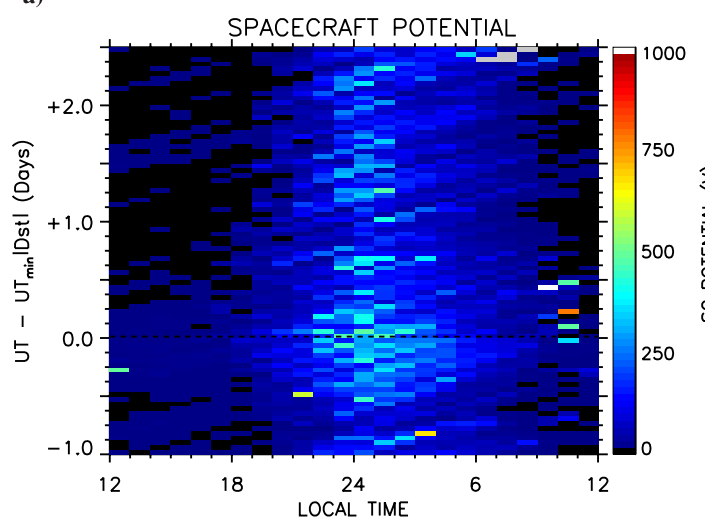

c)

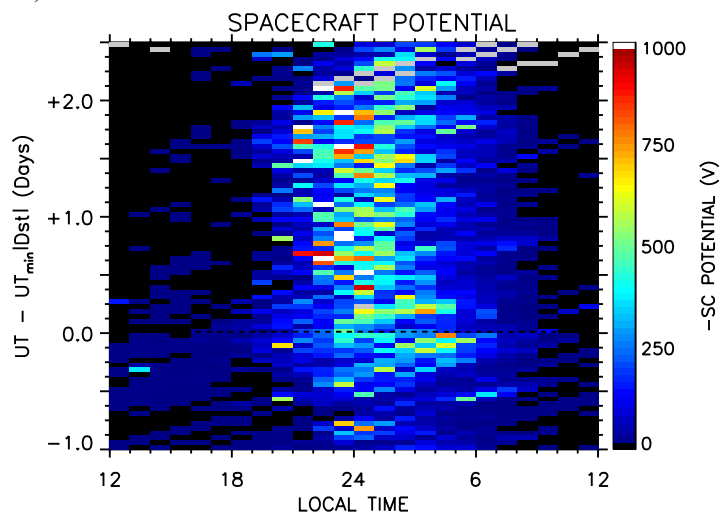

b)

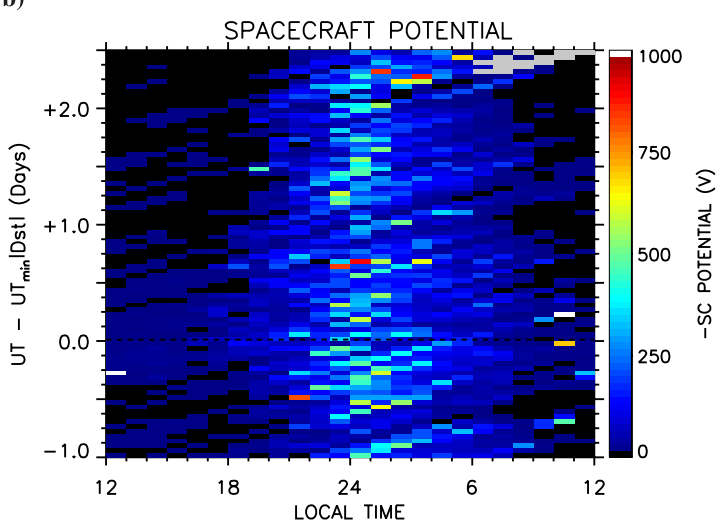

d)

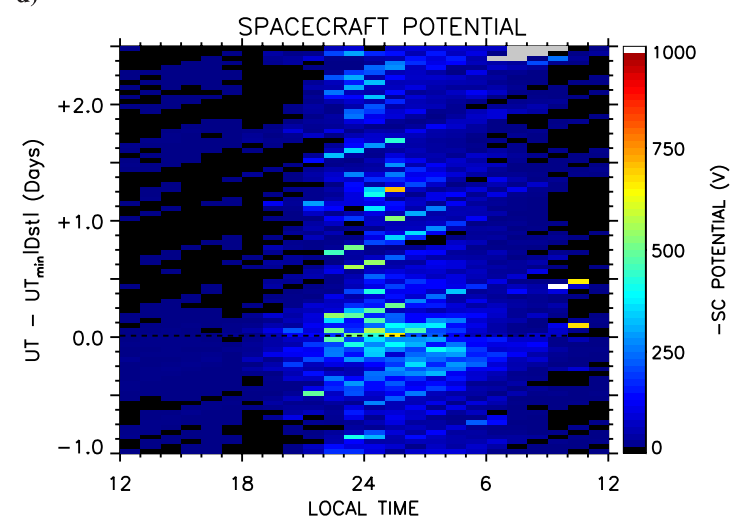

Figure 6. Same as Figure 5 except we remove all times when the spacecraft is in the Earth's shadow. The magnitude of the potential is much greater for the CIR events, compared with ICME events, and the elevated spacecraft potential lasts for a longer time.

[e.g., Terasawa et al., 1997; Borovsky et al., 1998], and since density in ICMEs is typically greater than that in CIRs, it is logical that CIR-driven storms should have a lesser density signature in the geosynchronous data, than ICME-driven storms. In addition, the ionospheric component of the plasma sheet, as measured at geosynchronous orbit, is very much enhanced at solar maximum [e.g., Denton et al., 2005]. During the extended period of enhanced convection during CIR events the plasma sheet which is injected to the inner magnetosphere via geosynchronous orbit has a density up to a factor of 2 lower than during the ICME events.

[22] The solar wind speed is also directly related to the temperature of the plasma sheet [Borovsky et al., 1998], with a higher temperature plasma sheet being formed under conditions of high solar wind speed. Since CIR-dominated solar wind is directly associated with high speed solar wind, it is also logical that CIR-driven storms should have a higher temperature signature in the geosynchronous data than ICME-driven storms.

[23] As shown in Figure 1, ICME- and CIR-driven storms tend to occur during different parts of the solar cycle. Comparison of the plasma sheet properties during the two kinds of storm is therefore complicated by the role of the ionosphere. Large changes in composition between solar maximum and solar minimum are known to occur in the ionosphere [e.g., Heelis et al., 1990; West et al., 1997; Denton and Bailey, 2001], and such compositional changes may be reflected in the inner magnetosphere and plasma sheet composition [e.g., Young et al., 1982; Lockwood et al., 1985; Yau et al., 1985; Lennartsson, 1988; Daglis et al., 1999; Nosé et al., 2000; Fu et al., 2001; Denton et al., 2005]. Although the LANL/MPA instrument is a simple E/q analyzer, and the production moments are calculated under the assumption that all ions are protons, Denton et al. [2005] outlined a method by which, under certain circumstances, the oxygen and hydrogen ion densities may be inferred. To investigate the composition of the plasma at geosynchronous orbit for ICME- and CIR-driven storms, the averaged inferred $\mathrm{O}^{+}$and $\mathrm{H}^{+}$densities are calculated between 2300 and 0200 LT as a function of epoch time, using the same method as described by Denton et al. [2005]. We do not repeat the description of that method here, simply noting that the method is only considered valid when: (1) the hot plasma sheet population measured by LANL/MPA is much denser than the population of cold plasma from the plasmasphere and, (2) the contribution of higher-energy populations is negligible. These conditions are typically satisfied in the region close to local midnight, when a fresh plasma sheet population is present. Since the events studied are storm periods, it is likely that the plasma is freshly injected from the tail and it is assumed that the conditions described above are met.

[24] Figure 7 shows the inferred $\mathrm{O}^{+}$and $\mathrm{H}^{+}$densities, and their ratio, averaged between 2300 and $0200 \mathrm{LT}$ as a function of epoch time for Group A, B, and C events. 

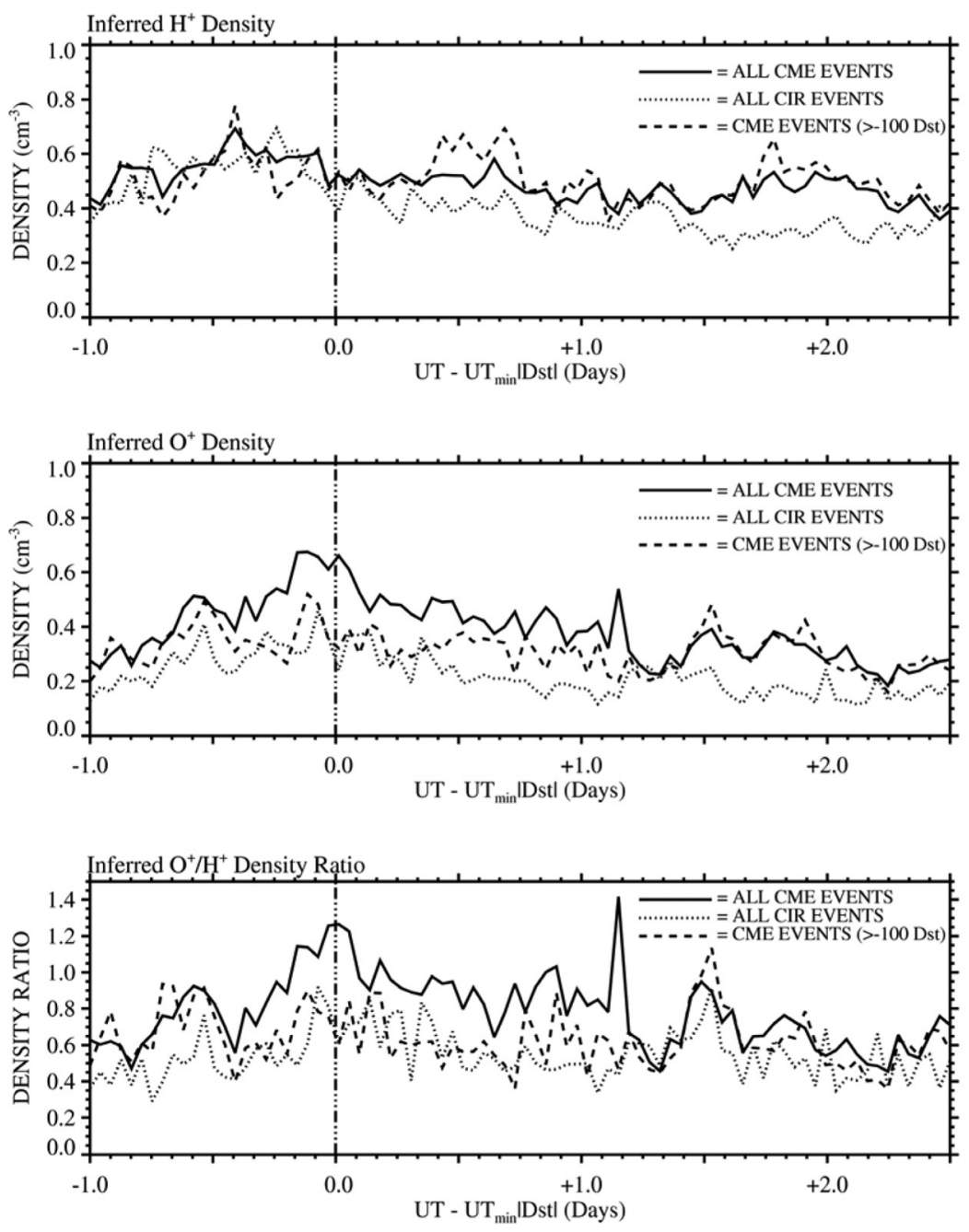

Figure 7. The averaged inferred $\mathrm{H}^{+}$and $\mathrm{O}^{+}$densities and their ratio, as a function of storm time, for Group A, Group B, and Group C events, between 2300 and 0200 LT.

There is some evidence of an increase in the $\mathrm{H}^{+}$component of the plasma sheet, for all types of storm, which begins during the main phase, around 12 to 16 hours prior to the minimum storm Dst. The inferred $\mathrm{H}^{+}$density then appears to fall slightly toward minimum Dst, and remains fairly static during the recovery phase. The maximum density is between 0.6 and $0.8 \mathrm{~cm}^{-3}$, while the minimum density is around $0.3 \mathrm{~cm}^{-3}$. There appears to be little difference in the $\mathrm{H}^{+}$density between Group A and Group B events, with the $\mathrm{H}^{+}$density in both groups slightly higher on average than during the Group $\mathrm{C}$ events.

[25] The inferred $\mathrm{O}^{+}$density appears to vary significantly more than the $\mathrm{H}^{+}$density through the storms, a result in agreement with the storm-time ion composition behavior noted by Denton et al. [2005]. In addition, the increase in $\mathrm{O}^{+}$density is greatest for the Group A events than for the Group B and Group C events, indicating more heavy-ion content in the plasma sheet for larger storms driven by ICMEs. The $\mathrm{O}^{+} / \mathrm{H}^{+}$density ratio also shows this feature, suggesting that for the Group A events, the $\mathrm{O}^{+}$density and $\mathrm{H}^{+}$densities may be comparable during the main phase of the storm. The $\mathrm{O}^{+}$density appears to be lowest for the Group $\mathrm{C}$ events, indicating that ICME-driven storms are oxygen-rich, whilst CIR storms are oxygen-poor. Although these results are inferred from a technique that has yet to be validated with other independent measurements, they are in agreement with other studies of the storm-time and solar cycle variation of ion composition and ring current composition [e.g., Young et al., 1982; Yau et al.,. 1985; Vennerstrøm and Friis-Christensen, 1996; Nosé et al., 2000; Hamilton et al., 1988] which indicate solar cycle and geomagnetic activity variations in ionospheric outflow and subsequent plasma sheet composition. Denton et al. [2005] have recently shown a clear factor of two variation in the hot electron density at geosynchronous orbit over a solar cycle. Since the solar wind composition is fairly constant over a solar cycle, it can be assumed that either (1) the solar cycle variation in the ionosphere is responsible for this behavior, or (2) the ICME and CIR storms operate differently in uplifting $\mathrm{O}^{+}$from the ionosphere and delivering it to the plasma sheet. ICMEs typically occur close to solar maximum, when outflow of the heavier ions (e.g., $\mathrm{He}^{+}$and $\mathrm{O}^{+}$) is maximized. CIRs typically occur close to solar minimum, when outflow of the heavier ions is minimized. Thus, the initial $\mathrm{O}^{+}$and $\mathrm{H}^{+}$densities prior to the storm are likely determined by the phase of the solar 
Table 1. A Summary of the Effects of ICME- and CIR-Dominated Solar Wind Detected in the Plasma at Geosynchronous Orbit

\begin{tabular}{|c|c|c|}
\hline & ICME Storms & CIR Storms \\
\hline Solar wind conditions & $\begin{array}{c}\text { Ejecta from sun produce an } \\
\text { isolated peak in the solar } \\
\text { wind density which can last } \\
\text { hours or days. }\end{array}$ & $\begin{array}{l}\text { Interaction of fast and slow } \\
\text { solar wind. High solar wind } \\
\text { speed which declines slowly } \\
\text { (hours or days). }\end{array}$ \\
\hline Magnetospheric convection & $\begin{array}{c}\text { Isolated period of elevated } \\
\text { convection returning to low } \\
\text { levels usually over a period } \\
\text { of hours. }\end{array}$ & $\begin{array}{c}\text { Extended period of enhanced } \\
\text { convection which can } \\
\text { last days. }\end{array}$ \\
\hline $\begin{array}{l}\text { Plasma sheet ion density } \\
\qquad(\sim 1-45 \mathrm{keV})\end{array}$ & $\begin{array}{l}\text { Initial density enhancement } \\
\text { close to local midnight. } \\
\text { Density peaks close to } \\
\text { minimum Dst and highest } \\
\text { between midnight and } \\
\text { dawn. Plasma sheet density } \\
\text { regularly in excess of } 1.2 \mathrm{~cm}^{-3} \text {. } \\
\text { Density remains } \\
\text { elevated for upwards of } 24 \text { hours. }\end{array}$ & $\begin{array}{c}\text { Initial density enhancement } \\
\text { close to local midnight. } \\
\text { Density peaks close to } \\
\text { minimum Dst and highest } \\
\text { between midnight and dawn. } \\
\text { Plasma sheet density } \\
\text { occasionally in excess of } 1.2 \mathrm{~cm}^{-3} \\
\text { Density remains } \\
\text { elevated for less than } \\
24 \text { hours. }\end{array}$ \\
\hline $\begin{array}{l}\text { Plasma sheet ion temperature } \\
\qquad(\sim 1-45 \mathrm{keV})\end{array}$ & $\begin{array}{l}\text { Temperature weakly } \\
\text { correlated with storm } \\
\text { activity, with slight increase } \\
\text { close to local noon near } \\
\text { minimum Dst. }\end{array}$ & $\begin{array}{l}\text { Temperature increase during } \\
\text { storm between local noon } \\
\text { and midnight. Temperature } \\
\text { remains elevated for days. }\end{array}$ \\
\hline $\begin{array}{l}\text { Plasma sheet electron density } \\
\qquad(\sim 1-45 \mathrm{keV})\end{array}$ & $\begin{array}{l}\text { Initial density enhancement } \\
\text { in post-midnight region. } \\
\text { Density peaks close to } \\
\text { minimum Dst and highest } \\
\text { between midnight and } \\
\text { dawn. Plasma sheet density } \\
\text { regularly in excess of } 1.4 \mathrm{~cm}^{-3} \text {. }\end{array}$ & $\begin{array}{l}\text { Initial density enhancement } \\
\text { in post-midnight region. } \\
\text { Density peaks close to } \\
\text { minimum Dst and highest } \\
\text { between midnight and dawn. } \\
\text { Plasma sheet density } \\
\text { occasionally in excess of } \\
1.4 \mathrm{~cm}^{-3} \text {. }\end{array}$ \\
\hline $\begin{array}{l}\text { Plasma sheet electron temperature } \\
\qquad(\sim 1-45 \mathrm{keV})\end{array}$ & $\begin{array}{c}\text { Temperature correlated } \\
\text { with storm phase. } \\
\text { Temperature increase } \\
\text { during main phase close to } \\
\text { local midnight. } \\
\text { Temperature quickly } \\
\text { returns to pre-storm levels } \\
\text { during recovery phase. }\end{array}$ & $\begin{array}{l}\text { Temperature increase during } \\
\text { storm, with maximum } \sim 3000 \mathrm{eV} \\
\text { close to local midnight. } \\
\text { Temperature remains } \\
\text { elevated for days. }\end{array}$ \\
\hline Plasma sheet composition & $\begin{array}{l}\text { Evidence for enriched } \mathrm{O}^{+} \\
\text {and to a lesser extent, } \mathrm{H}^{+} \text {density, } \\
\text { during main phase } \\
\text { of storm - likely solar cycle related. }\end{array}$ & $\begin{array}{l}\text { Slight enhancement in } \mathrm{O}^{+} \\
\text {during main phase. }\end{array}$ \\
\hline Spacecraft potential & Elevated during storm. & $\begin{array}{l}\text { Highly elevated in } \\
\text { magnitude. Effects last days. }\end{array}$ \\
\hline
\end{tabular}

cycle [Denton et al., 2005]. Superimposed on this behavior is a storm time change in the density of each ion, that appears to be greater for the $\mathrm{O}^{+}$ions than the $\mathrm{H}^{+}$ions, and is greatest during the largest ICME-driven storms.

\section{Conclusions and Summary}

[26] The analyses detailed above show that there are significant differences in the geosynchronous plasma environment during ICME-driven storms when compared with CIR-driven storms. The averaged hot electron and hot ion densities increase significantly during the main phase of both types of storm, but the increase is greater for ICME events than for CIR events, even when the size of the storm, as measured by the Dst index, is roughly equivalent. Further, we find that the hot electron and hot ion temperatures are enhanced during both types of storm, but are more enhanced, and for longer, during CIR events than ICME events. We find ICMEs play a greater role in regulating the plasma sheet density, whilst CIRs play a greater role regulating the plasma sheet temperature. Other significant features of ICME- and CIR-driven storms, as observed at geosynchronous orbit are highlighted in Table 1.

[27] To summarize, we note the following:

[28] 1. The density of a significant source population for the ring current, the electron and ion plasma sheet, is likely to be more enhanced for ICME events than for CIR events,

[29] 2. The temperature of the plasma sheet is, on average, significantly elevated for a longer time during CIR events than during ICME events,

[30] 3. Inferred density measurements indicate ICME storms are rich in $\mathrm{O}^{+}$compared to CIR storms. The $\mathrm{O}^{+}$ fraction is greater for the larger storms,

[31] 4. The magnitude of spacecraft potential is, on average, significantly elevated for a longer time during CIR events than during ICME events - CIR events create 
a dangerous charging environment for a longer time period than ICME events.

[32] Acknowledgments. The authors would like to thank the World Data Centre $\mathrm{C} 1$ at RAL, UK for the Dst and Kp data, and all members of the WIND team for access to the solar wind data. M. H. Denton wishes to thank P. H. Janzen for many helpful discussions. The work at Los Alamos was performed under the auspices of the U.S. Department of Energy, with partial support from the NASA Living With a Star program.

[33] Shadia Rifai Habbal thanks Edward J. Smith and another referee for their assistance in evaluating this paper.

\section{References}

Bame, S. J., D. J. McComas, M. F. Thomsen, B. L. Barraclough, R. C. Elphic, J. P. Glore, J. C. Chavez, E. P. Evans, and F. J. Wymer (1993), Magnetospheric plasma analyzer for spacecraft with constrained resources, Rev. Sci. Instrum., 64, 1026-1033.

Borovsky, J. E., and M. H. Denton (2006), The differences between CMEdriven storms and CIR-driven storms, J. Geophys. Res., doi:10.1029 2005JA011447, in press.

Borovsky, J. E., M. F. Thomsen, R. C. Elphic, T. E. Cayton, and D. J. McComas (1998), The transport of plasma sheet material from the distant tail to geosynchronous orbit, J. Geophys. Res., 103, 20,297-20,331.

Cane, H. V., and I. V. Richardson (2003), Interplanetary coronal mass ejections in the near-Earth solar wind during 1996-2002, J. Geophys. Res., 108(A4), 1156, doi:10.1029/2002JA009817.

Crooker, N. U., and E. W. Cliver (1994), Postmodern view of M-regions, J. Geophys. Res., 99, 23,383-23,390.

Daglis, I. A., G. Kasotakis, E. T. Sarris, Y. Kamide, and B. Wilken (1999) Variations of the ion composition during an intense magnetic storm and their consequences, Phys. Chem. Earth, 24, 229-232.

Denton, M. H., and G. J. Bailey (2001), Modelling the high altitude electron temperature: A modified thermal conductivity, Dyn. Atmos. Oceans, $34,365-381$

Denton, M. H., M. F. Thomsen, H. Korth, S. Lynch, J. C. Zhang, and M. W. Liemohn (2005), Bulk plasma properties at geosynchronous orbit, J. Geophys. Res., 110, A07223, doi:10.1029/2004JA010861.

Dmitriev, A. V., N. B. Crosby, and J.-K. Chao (2005), Interplanetary sources of space weather disturbances in 1997 to 2000, Space Weather, 3, S03001, doi:10.1029/2004SW000104.

Friedel, R. H. W., H. Korth, M. G. Henderson, M. F. Thomsen, and J. D. Scudder (2001), Plasma sheet access to the inner magnetosphere, J. Geophys. Res., 106, 5845-5858.

Fu, S. Y., B. Wilken, Q. G. Zong, and Z. Y. Pu (2001), Ion composition variations in the inner magnetosphere: Individual and collective storm effects in 1991, J. Geophys. Res., 106, 29,683-29,704.

Garrett, H. B. (1981), The charging of spacecraft surfaces, Rev. Geophys., $19,577$.

Gonzalez, W. D. B. T. Tsurutani, and A. L. Clúa de Gonzalez (2002), Geomagnetic storms contrasted during solar maximum and solar minimum, Adv. Space Res., 30, 2301-2304.

Gosling, J. T., J. R. Asbridge, S. J. Bame, and W. C. Feldman (1978), Solar wind stream interfaces, J. Geophys. Res., 83, 1401-1412.

Gosling, J. T., G. Borrini, J. R. Asbridge, S. J. Bame, W. C. Feldman, and R. T. Hansen (1981), Coronal streamers in the solar wind at $1 \mathrm{AU}$, J. Geophys. Res., 86, 5438-5448.

Hamilton, D. C., G. Gloeckler, F. M. Ipavich, W. Studemann, B. Wilken, and G. Kremser (1988), Ring current development during the great geomagnetic storm of February 1986, J. Geophys. Res., 93, 14,343-14,355

Heelis, R. A., W. B. Hanson, and G. J. Bailey (1990), Distributions of He+ at middle and equatorial latitudes during solar maximum, J. Geophys. Res., 95, 10,313-10,320.

Hundhausen, A. J. (1993), Sizes and locations on coronal mass ejections: SMM observations from 1980 and 1984-1989, J. Geophys. Res., 98, $13,177-13,200$.

Jordanova, V. K., J. U. Kozyra, A. F. Nagy, and G. V. Khazanov (1997), Kinetic model of the ring current-atmosphere interactions, J. Geophys. Res., 102, 14,279-14,291.

Kamide, Y., et al. (1998), Current understanding of magnetic storms: Storm-substorm relationships, J. Geophys. Res., 103, 17,705-17,728.

Knipp, D. J., et al. (1998), An overview of the early November 1993 geomagnetic storm, J. Geophys. Res., 103, 26,197.

Korth, H., and M. F. Thomsen (2001), Plasma sheet access to geosynchronous orbit: Generalization to numerical field models, J. Geophys. Res. $106,29,655-29,667$

Korth, H., M. F. Thomsen, J. E. Borovsky, and D. J. McComas (1999), Plasma sheet access to geosynchronous orbit, J. Geophys. Res., 104, $25,047-25,061$
Lavraud, B., M. H. Denton, M. F. Thomsen, J. E. Borovsky, and R. H. Friedel (2005), Superposed epoch analysis of cold, dense plasma sheet access to geosynchronous orbit, Ann. Geophys., 23, 1-11.

Lennartsson, W. (1988), Comparison of plasma sheet ion composition with the IMF and solar wind, Adv. Space. Res., 8, 135-138.

Liemohn, M. W., J. U. Kozyra, C. R. Clauer, and A. J. Ridley (2001), Computational analysis of the near-Earth magnetospheric current system during two-phase decay storms, J. Geophys. Res., 106, 29,531-29,542. Lockwood, M., J. H. Waite Jr., T. E. Moore, J. F. E. Johnson, and C. R. Chappell (1985), A new source of suprathermal $\mathrm{O}^{+}$near the dayside polar cap boundary, J. Geophys. Res., 90, 4099-4116.

MacQueen, R. M., A. J. Hundhausen, and C. W. Conover (1986), The propagation of coronal mass ejection transients, J. Geophys. Res., 91, $31-38$.

Mann, I. R., T. P. O'Brien, and D. K. Milling (2004), Correlations between ULF wave power, solar wind speed, and relativistic electron flux in the magnetosphere: Solar cycle dependence, J. Atmos. Sol. Terr. Phys., 66, 187.

McComas, D. J., S. J. Bame, B. L. Barraclough, J. R. Donart, R. C. Elphic, J. T. Gosling, M. B. Moldwin, K. R. Moore, and M. F. Thomsen (1993), Magnetospheric plasma analyzer: Initial three-spacecraft observations from geosynchronous orbit, J. Geophys. Res., 98, 13,453-13,465.

Nosé, M., S. Ohtani, A. T. Y. Liu, S. P. Christon, R. W. McEntire, D. J. Williams, T. Mukai, Y. Saito, and K. Yumoto (2000), Change of energetic ion composition in the plasma sheet during substorms, J. Geophys. Res., $105,23,277-23,286$

Paulikas, G. A., and J. B. Blake (1976), Modulation of trapped energetic electrons at $6.6 \mathrm{R}_{\mathrm{e}}$ by the direction of the magnetic field, Geophys. Res. Lett., 3, 277-280.

Smith, E. J., and J. H. Wolf (1976), Observations of interaction regions and co-rotating shocks between one and five AU: Pioneer 10 and 11, Geophys. Res. Lett., 3, 137-140.

Terasawa, T., et al. (1997), Solar wind control of density and temperature in the near-Earth plasma sheet: WIND/GEOTAIL collaboration, Geophys. Res. Lett., 24, 935.

Thomsen, M. F. (2004), Why Kp is such a good measure of magnetospheric convection, Space Weather, 2, S11004, doi:10.1029/2004SW000089.

Thomsen, M. F., J. E. Borovsky, D. J. McComas, and M. R. Collier (1998), Variability of the ring current source population, Geophys. Res. Lett., 25 , $3481-3484$

Thomsen, M. F., E. Noveroske, J. E. Borovsky, and D. J. McComas (1999), Calculation of moments from measurements by the Los Alamos magnetospheric plasma analyzer, LA Rep. LA-13566-MS, Los Alamos Natl. Lab., Los Alamos, N. M.

Thomsen, M. F., J. Birn, J. E. Borovsky, K. Morzinski, D. J. McComas, and G. D. Reeves (2001), Two-satellite observations of substorm injections at geosynchronous orbit, J. Geophys. Res., 106, 8405-8416.

Thomsen, M. F., J. E. Borovsky, R. M. Skoug, and C. W. Smith (2003), Delivery of cold, dense plasma sheet material into the near-Earth region, J. Geophys. Res., 108(A4), 1151, doi:10.1029/2002JA009544.

Tsurutani, B. T., W. D. Gonzalez, A. L. C. Gonzalez, F. Tang, J. K. Arballo, and M. Okada (1995), Interplanetary origin of geomagnetic activity in the declining phase of the solar cycle, J. Geophys. Res., 100, 21,717-21,733. Vennerstrøm, X., and X. Friis-Christensen (1996), Long term and solar cycle variation of the ring current, J. Geophys. Res., 101, $24,735$.

West, K. H., R. A. Heelis, and F. J. Rich (1997), Solar activity variations in the composition of the low latitude ionosphere, J. Geophys. Res., 102, 295-302.

Wilken, B., Q.-G. Zong, T. Doke, T. Mukai, T. Yamamoto, G. D. Reeves, K. Maezawa, S. Kokubun, and S. Ullaland (1998), Substorm activity on January 11, 1994: Geotail observations in the distant tail during the leading phase of a corotating interaction region, J. Geophys. Res., 103, $17,671-17,689$

Wilken, B., Q.-G. Zong, G. D. Reeves, T. Doke, and T. Yamamoto (1999), Geoactivity in response to CIR/CME events - A synoptic view, Phys. Chem. Earth C, 24(1-3), 113-117.

Wrenn, G. L., and R. J. K. Smith (1996), Probability factors governing ESD effects in geosynchronous orbit, IEEE Trans. Nucl. Sci., 43, 2783

Yau, A. W., P. H. Beckworth, W. K. Peterson, and E. G. Shelley (1985), Long term (solar cycle) and seasonal variations of upflowing ionospheric ion events at DE 1 altitudes, J. Geophys. Res., 90, 63956407

Young, D. T., H. Balsiger, and J. Geiss (1982), Correlations of magnetospheric ion composition with geomagnetic and solar activity, J. Geophys. Res., 87, 9077-9096.

Zhang, J.-C., M. W. Liemohn, J. U. Kozyra, B. J. Lynch, and T. H. Zurbuchen (2004), A statistical study of the geoeffectiveness of magnetic clouds during high solar activity years, J. Geophys. Res., 109, A09101, doi:10.1029/2004JA010410. 
Zong, Q.-G., et al. (1997), Geotail observations of energetic ion species and magnetic field in plasmoid-like structures in the course of an isolated substorm event, J. Geophys. Res., 102, 11,409-11,428.

J. E. Borovsky, M. G. Henderson, B. Lavraud, R. M. Skoug, and M. F Thomsen, MS D466 Los Alamos National Laboratory, Los Alamos, NM 87545,USA. (jborovsky@lanl.gov; mghenderson@lanl.gov; lavraud@lanl. gov; rskoug@lanl.gov; mthomsen@lanl.gov)
M. H. Denton, School of Physics and Astronomy, University of Southampton, Southampton, SO17 1BJ, UK. (mdenton@phys.soton.ac.uk) M. W. Liemohn and J. C. Zhang, Atmospheric, Oceanic and Space Sciences Department, University of Michigan, 2455 Hayward Street, Ann Arbor, MI 48109, USA. (liemohn@umich.edu; jichunz@engin. umich.edu)

R. L. McPherron, Institute of Geophysics and Planetary Physics, University of California, Los Angeles, Los Angeles, CA 90095, USA. (mcpherron@igpp.ucla.edu) 